\title{
Vehicle tracker system design based on GSM and GPS interface using arduino as platform
}

\author{
Narcisa T. Morallo \\ College of Engineering and Architecture, Negros Oriental State University, Dumaguete, Philippines
}

\begin{tabular}{l} 
Article Info \\
\hline Article history: \\
Received Jan 14, 2021 \\
Revised Apr 23, 2021 \\
Accepted May 1, 2021 \\
\hline
\end{tabular}

\section{Keywords:}

Arduino uno

Engineering processes and systems

Experimental method Global positioning system

Global system for mobile communications

\begin{abstract}
Global positioning system (GPS) tracker is an innovative technology that is able to track the position of vehicle using global satellite system. In this paper, vehicle tracker system design that is derived from global positioning system and global system for mobile communication (GSM) interface with the use of Arduino Uno board as platform is proposed and presented. Technology in Arduino, GSM, and GPS is studied.GPS module receives the coordinates from the satellite. The GPS coordinates are sent to users in the form of SMS through SIM900A GSM module. By using Google Maps, the exact location of the vehicle can be located. Arduino microcontroller is the gateway to all GPS and GSM hardware and software communication in the system. The design represents that GSM and GPS interface with the use of Arduino Uno board as platform can really make vehicle tracking more efficient and convenient since it can work in any weather conditions and provide real-time location of objects. Automatic display of the coordinate's geographical location in a map should be integrated in future design.
\end{abstract}

This is an open access article under the CC BY-SA license.

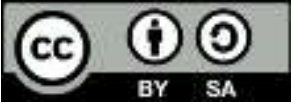

\section{Corresponding Author:}

Narcisa T. Morallo

College of Engineering and Architecture

Negros Oriental State University

Bajumpandan, Dumaguete City, Philippines

Email: narcisamorallo@gmail.com

\section{INTRODUCTION}

Globally, vehicles on the road are increasing. Keeping track of vehicles ensures security, route management and significant cost-savings. Technology in global positioning system (GPS) tracker system is utilized in vehicle management. In this paper, a vehicle tracker based on global system for mobile communication (GSM) and GPS Interface using Arduino as platform designed to track vehicles remotely using GSM network. While previous works uses internet to track vehicles. This is a low-cost design with materials readily available. The importance of this project is for cost-savings and security.

According to Grand View Research, Inc., the GPS market size is expected to reach USD 146.4 billion by 2025 as shown in Figure 1. A compound annual growth rate of $18.4 \%$ is anticipated during the forecast period. Growing embracement of location-based services such as e-hailing and food delivery around the world propels the demand for GPS.

GPS also functions as a satellite-based navigation system that works in any weather conditions and provides real-time location of objects. GPS sensors can be used in location-based services, fleet vehicle management, scientific exploration, horse racing, government usage, and many others as shown in Figure 2. Real-time data can help in monitoring and planning proper means for situation resolution. 


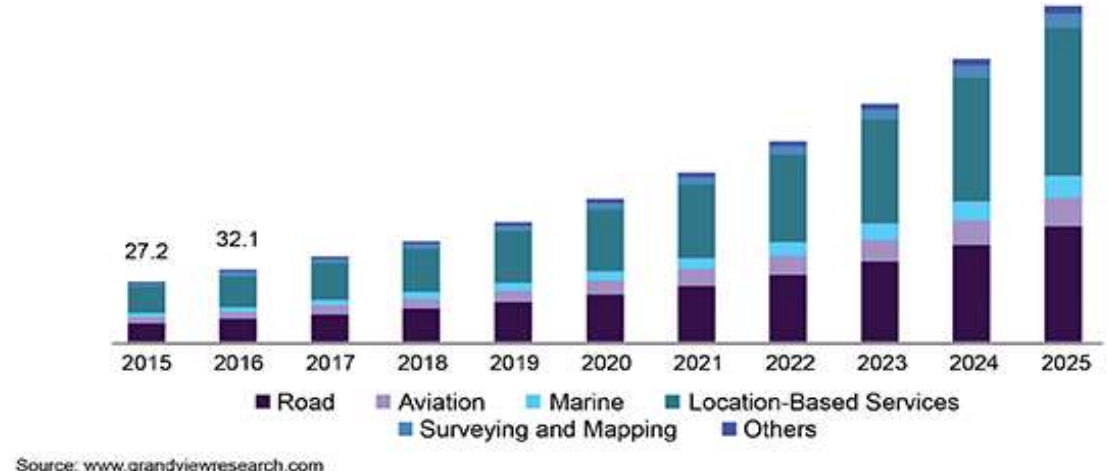

Figure 1. Global GPS market size

$\mathbf{Z}$

Global GPS market share, by application, $2017(\%)$

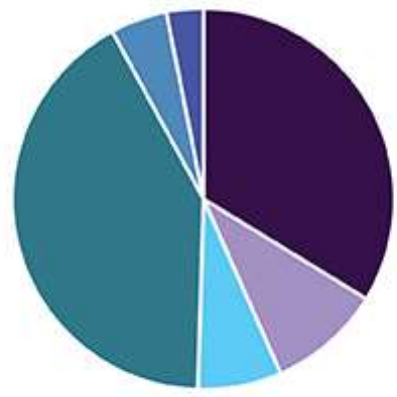

- Road

E Aviation

In Marine

E Location-Based Services

- Surveying and Mapping

Others

Source, mww. grandviewresearch.com

Figure 2. Global GPS market share

GPS software allows geotagging and location positioning for social media platforms divulging users to diverseness of location-specific information. GPS system integrated with GSM gives the user the privilege to quickly track vehicles and other types of movable assets. Alli et al., Dutta et al., and Kadiri et al., develop vehicle anti-theft system using GSM/GPRS [1]-[3]. From a mobile phone, vehicle status is monitored and can execute command controls like remotely off gasoline supply. For added security, Ganapathy et al., include a finger verification feature [4]. GT06N, is a GPS device use in tracking real time location of vehicles using SMS or the internet [5].

Many researches designed a system that provides latitude and longitude coordinates in real time [6]-[13]. This short message service (SMS) based tracking system utilizes GPS and GSM modules. While Oheka and Tu C designed a tracker that detects a vehicle that tailed the host vehicle [14]. Verma et al., Hidayat, and Mishra et al., developed a tracker system use to display the information location of a public utility vehicle using geographic information system (GIS), radio frequency identification (RFID) and GSM [7]-[9]. With arrival information at predefined stops, passenger's occupancy improved.

Tracking road accident can save life, Routh et al., and Lonkar et al., designed a system that will locate where the accident occured and send SMS to ambulance [15]-[16]. Real time tracking can avoid delay to medication. Priyadarshni et al., uses micro electro mechanical system (MEMS) sensor to detect whenever an accident occurs [17]. Vehicles are contributor to air pollution. Monitoring vehicle emission using MQ-7 gas sensor and GPS module can create awareness in the community [18]-[19].

Yang et al., developed vehicle tracking for intelligent transportation based on detection-based tracking (DBT) framework [20]. The you only look once (YOLO) model used improves vehicle detection precision. For dense road scene interpretation in intelligent driving, vehicle and lane tracking, IT operation 
management (ITOM) is utilized [21]. Other rseraches designed a path tracker for self-driving cars (SDC) using a nonlinear model-predictive-control (NMPC) approach [21]-[24].

Ramli et al., designed an open source LoRA based vehicle tracker using GIS, Arduino and GPS to monitor the speed and location of boats in waters [25]. High speed boats can have an impact to the ecological system. The system inspired to protect UNESCO Kilim Karst Geoforest Park in Malaysia.

\section{RESEARCH METHOD}

Vehicle tracker system is equipped with GPS module Board NEO-6m, which provides the GPS coordinates of vehicle location. The GPS coordinates are sent to users in the form of SMS through SIM900A GSM module. By using Google Maps, the exact location of the vehicle can be located.

In this study, designing of vehicle tracker system based on GPS and GSM interface using Arduino Uno board as platform is presented. Arduino microcontroller is the gateway to all GPS and GSM hardware and software communication in the system. The required hardware materials in this design are Arduino Uno, GPS module Board NEO-6m, and GSM module SIM900A. Arduino is an open hardware development board that can be used for designing and constructing devices. Just as seen in Figure 3, the microcontroller consists of 6 analog inputs, a 16-MHZ ceramic resonator and 14 digital input-output pins.

GPS is used to define the coordinates, longitudes, and latitudes of the Earth position with the right synchronized universal time (UTC). The GPS module receives the coordinates of the satellite. The GPS module transmits data for monitoring the exact location in real time and in NMEA format. It begins with \$GPGGA and includes time, coordinates, and other key information. GPGGA stands for Global Positioning System Fixed Data.

The GPS satellite navigation system provides the user with location and time information in all weather conditions. As seen in the Figure 4, the three components of the GPS are space, power, and user section. The space section is made up of GPS satellites. GPS satellites are deployed on orbits around the earth at an altitude of more or less $20,000 \mathrm{~km}$ and travel around the earth in 12-hour intervals. Ground control stations are the control, tracking, control and maintenance of satellite orbit at tolerance level. As a consumer segment, GPS receivers are various communication devices using GPS technology.

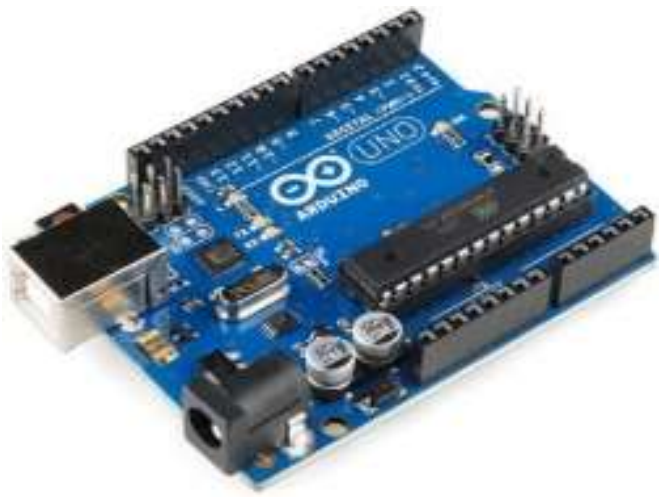

Figure 3. Arduino microcontroller

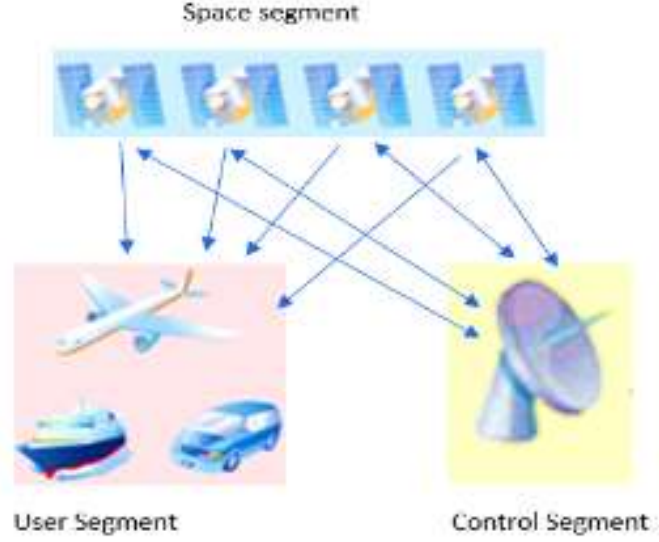

Figure 4. The three segments of GPS

GPS receiver, NEO-6m GPS module, provides a strong satellite search capability having a built-in ceramic antenna with a measurement of $25 \times 25 \times 4 \mathrm{~mm}$. Module status can be monitored with power and signal indicators. Through data backup battery, module can store data if the power is out. As shown in Figure 5, NEO-6M GPS module consistsof four pins, namely, VCC, TX, RX, and GND. The GPS module imparts with Arduino microcontroller through serial communication with the use of TX and RX pins.

Developed with a powerful single-chip processor that integrates the AMR926EJ-S core, the SIM900 GSM module, as shown in Figure 6, is a full GSM/GPRS quad-band solution. SIM900 provides GSM/GPRS $850 / 900 / 1800 / 1900 \mathrm{MHz}$ capacity for voice, SMS, data and fax with low power consumption. This module is designed for slim and compact designs measuring 24x24x3 mm.

The GSM-GPRS module is used to link a device to the GSM-GPRS system. The global system for mobile communication system (GSM) is an architecture used for mobile communication. Global packet radio 
service (GPRS) is an extension of GSM that allows higher data transmission speeds. GSM-GPRS MODEM is a wireless tool designed to link your device to the GSM and GPRS networks. The tool needs to have the same SIM card as the phones to start a network link. In addition, they consist of an international mobile equipment identity (IMEI) number identical to mobile phones for identification.

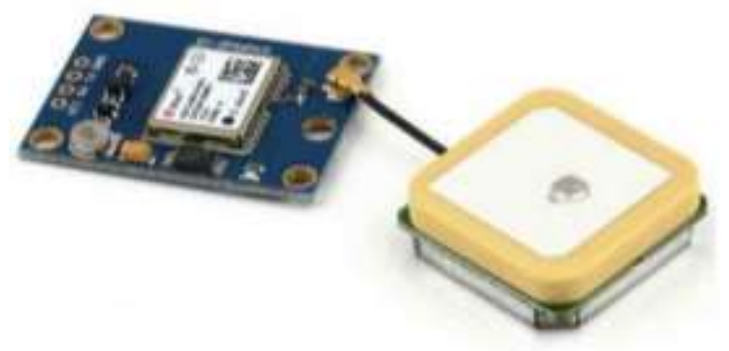

Figure 5. GPS module (NEO-6m)
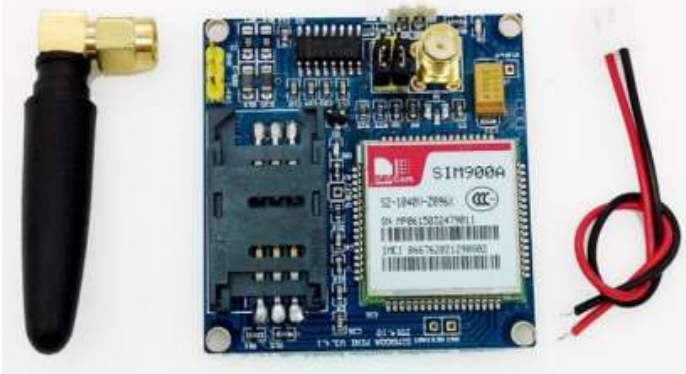

Figure 6. SIM900 GSM module

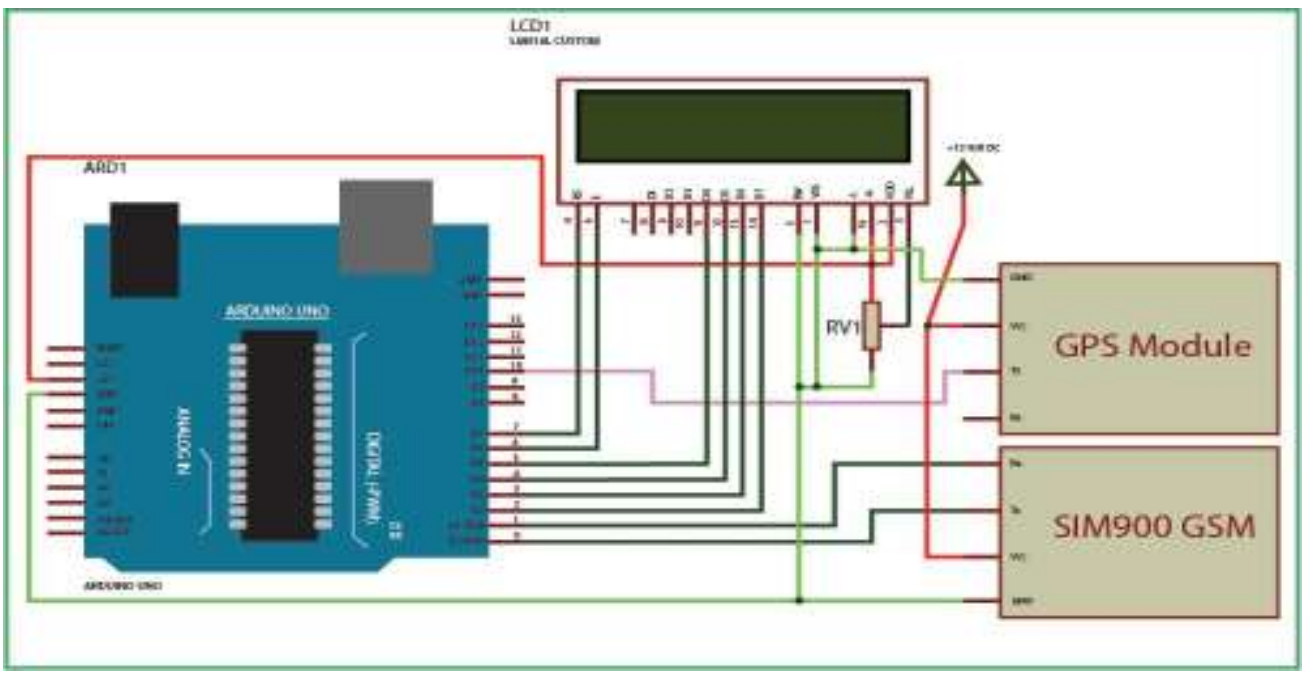

Figure 7. Schematic diagram of vehicle tracker

The schematic diagram of the device showing the pin connections between the Arduino, GSM and GPS modules is shown in Figure 7. In the GPS module, the Tx pin is immediately connected to the Arduino digital pin 10 while the RX pin of the GPS module is left open. Using the software serial library, serial communication on Pin 10 and 11 is allowed and used as Rx and Tx, respectively. Arduino Pins 0 and 1 are used for serial communication by default. However, serial communication on other Arduino digital pins can be permitted through the use of the software serial library. The GPS and GSM modules are operated by a 12-V supply, and the Rx and Tx pins of the GSM module are connected to the Tx and Rx of Arduino.

In this design, Arduino controls the entire process with a GSM module and a GPS receiver. Identifying the vehicle coordinates, using the GPS receiver, while sending the coordinates to the user via SMS, using the GSM module. After the program is uploaded to the Arduino, the coordinates of the vehicle can be determined. Arduino integrated development environment can be downloaded from Arduino. Arduino software (IDE) is an open-source, used in writing codes and compiling to the board. This software can be used in any Arduino board.

SMS is a text messaging service component of mobile device systems. Using standard communication protocols, mobile devices exchange short text messages. SMS is a built-in application of any mobile phone. An SMS "Track Vehicle" will be sent to the system to determine the coordinate of the subject. Figure 8 shows the snapshot of the SMS and the geographical location can be traced by google maps (Figure 9). 


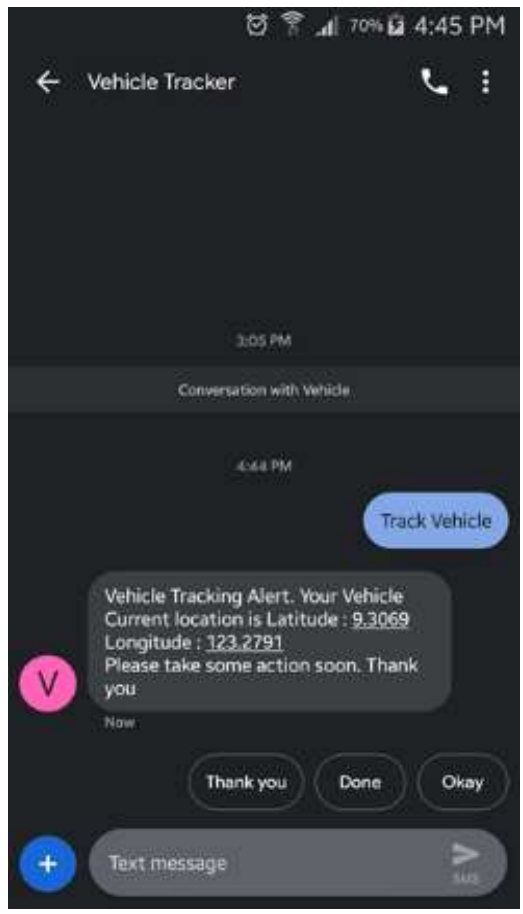

Figure 8. Graphical user interface

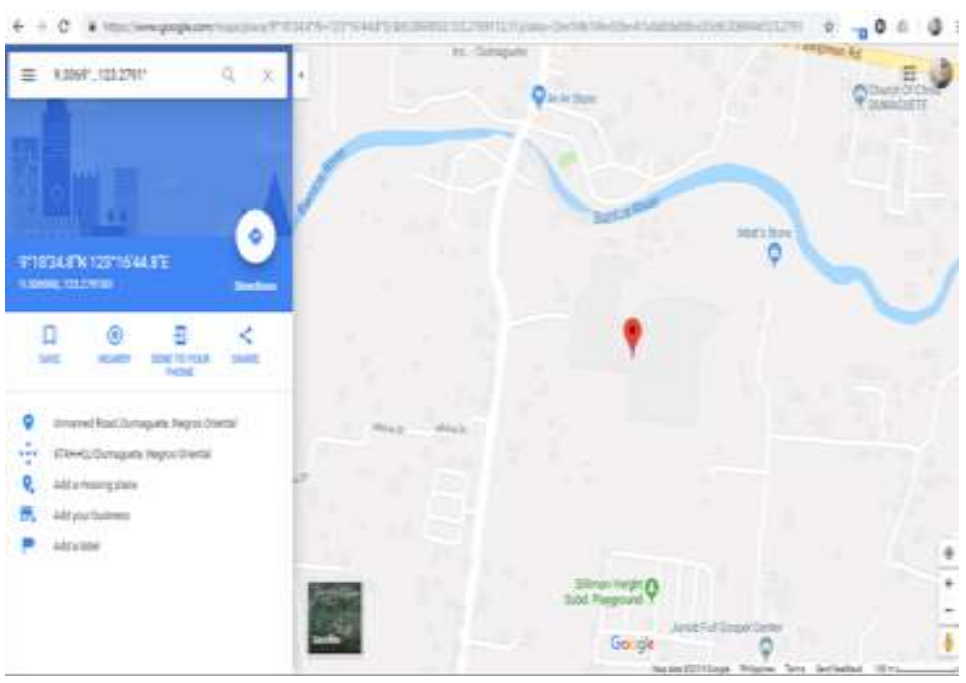

Figure 9. Geographical location

\section{RESULTS AND DISCUSSION}

In this paper, a design of vehicle tracker using GSM and GPS as interface with Arduino as platform is built. The working unit of the proposed system has been successfully developed as shown in Figure 10. GPS is a tool that can collect information from GPS satellites and measure the geographical location of the unit. Using the necessary software, the computer will show the location on the map and provide directions. The GPS is a Global Navigation Satellite system that is composed of a minimum of 24 networks, but recently, a number of 30 satellites are sent into orbit by the US Department of Defense.

An SMS will be forwarded to the system to locate the coordinate of the vehicle. GSM module receives the message sent and communicates to Arduino. Arduino reads the coordinates and sends it to user's phone through GSM module. The message carries the real-time coordinates of the vehicle location. By using Google Maps, the vehicle's geographical location will be determined through its position on a map. Real experiment data of vehicles' information location is shown in Table 1. Location tracking throughout the test were accurate.

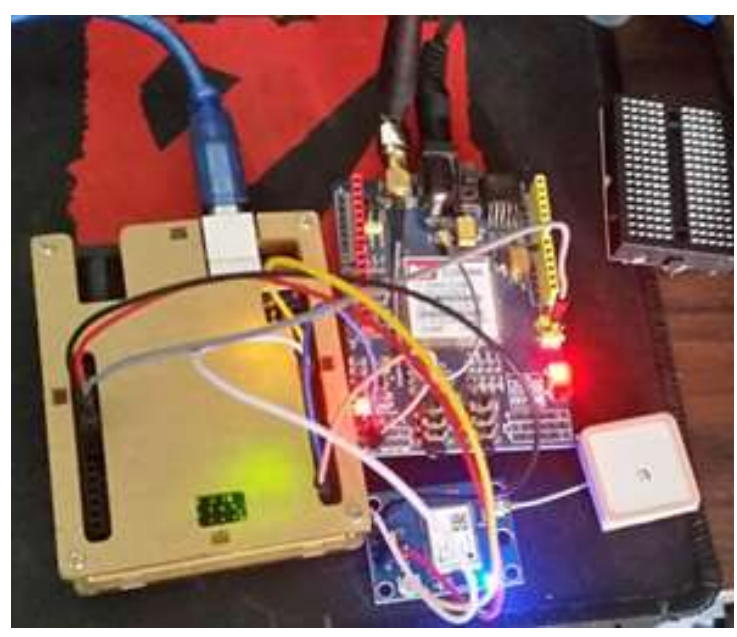

Figure 10. Vehicle tracker 
Time delay for the vehicle tracker to respond to the end user were observed during testing. A delay of an average of 52.5 seconds was recorded as shown in Table 2 using Philippine's two network providers, namely Globe and Smart. Delay is a result of localized poor network coverage due to interference in some areas the vehicle is travelling.

The design represents that GSM and GPS module interface with the use of Arduino Uno board as platform can really make vehicle tracking more efficient. Vehicle tracking can facilitate fuel management, prevent thefts, and provide driver's performance. With knowledge of vehicle's location, user can use its network attributes to optimize opportunities for productivity.

Table 1. Vehicles' location information

\begin{tabular}{cccc}
\hline Vehicle Location & Time (AM) & Latitude & Longitude \\
\hline A & $8: 00$ & 9.268769 & 123.292653 \\
B & $8: 07$ & 9.225804 & 123.285758 \\
C & $8: 15$ & 9.181969 & 123.256448 \\
D & $8: 31$ & 9.101624 & 123.198036 \\
E & $8: 54$ & 9.063050 & 123.033957 \\
F & $9: 12$ & 9.335756 & 122.861222 \\
G & $10: 03$ & 9.458651 & 122.570016 \\
\hline
\end{tabular}

Table 2. Time delay analysis

\begin{tabular}{ccc}
\hline $\begin{array}{c}\text { SIM in GSM } \\
\text { Module }\end{array}$ & $\begin{array}{c}\text { SIM in End } \\
\text { User }\end{array}$ & $\begin{array}{c}\text { Time Delay in } \\
\text { seconds }\end{array}$ \\
\hline Globe & Globe & 50 \\
Globe & Smart & 60 \\
Smart & Smart & 50 \\
Smart & Globe & 50 \\
\hline
\end{tabular}

\section{CONCLUSION}

A design of vehicle tracker system using GSM, GPS, and Arduino is successfully developed. A working design for the system provides an accurate and timely data. Throughout the test, location tracking was accurate. A tolerable average time delay of less than a minute was computed during the test. GPS and GSM modules are proved to be very efficient in designing a vehicle tracker with this platform. It is concluded that the design of vehicle tracker system using GSM module, GPS module and Arduino can save money and time and can facilitate fuel management, prevent thefts, and provide driver's performance. Furthermore, this is a low-cost design with readily available materials. Location animated in browser maybe included in future designs.

\section{REFERENCES}

[1] K. S. Alli, C. Ijeh-Ogboi and S.L. Gbadamosi, "Design and Construction of a Remotely Controlled Vehicle Anti-Theft System via GSM network,"in International Journal of Education and Research, vol. 3, no. 5, pp. 405-418, 2015.

[2] S. Dutta, M. Abrol, A. Kapoor, K. Singh and R. Kumar, "Anti-Theft Vehicle Device," in International Journal of Trend in Scientific Research and Development (IJTSRD), vol. 2, no. 4, pp.1460-1464, June 2018, doi: $10.31142 /$ ijtsrd11276.

[3] K. O. Kadiri and O. Adekoya, "Design of a GPS/GSM Based Anti-theft Car Tracker System," Current Journal of Applied Science and Technology, vol. 34, no. 3, pp. 1-8, 2019, doi: 10.9734/cjast/2019/v34i330132.

[4] B. S. Ganapathy, S. Akash, A. Prabhu, T. Kirubakaran, and S. Kumar, "Anti-Theft Protection of Vehicle by GSM \& GPS with Fingerprint Verification," International Journal of Advanced Engineering, Management and Science (IJAEMS), vol. 4, no. 4, 2018, doi: 10.22161/ijaems.4.4.7.

[5] A.P.U. Siahaan, "A Review of the GPS Tracker GT06N as the Vehicle Tracking Device," 2018, doi 10.31227/osf.io/rc8ma.

[6] K. Pachala, K. Bhavani, P. Priya, R. Nayak, and Y. Yeswanth, "GPS Based Vehicle Tracking System,” National Conference on Signal Processing \& Communication Systems, NCSPCS, 2010.

[7] S. Verma, A. Jamwal, S. Chauhan and S. Mohanty, "Vehicle Tracking System Using GPS and GSM," in Hura G., Singh A., Siong Hoe L. (eds), Advances in Communication and Computational Technology, Lecture Notes in Electrical Engineering vol. 668, Springer, Singapore, 2021, doi: 10.1007/978-981-15-5341-7_59.

[8] S. S. Hidayat, K. L. Novitasari, A. Syarifuddin, W. P. Pratiwi, S. Hardiningsih HS and R. A. Pratomo, "Anti-Theft Protection of Vehicle Using GPS Tracker \& Android Apps," in Logic: Jurnal Rancang Bangun danTeknologi, vol. 19, no. 2, pp. 78-83, 2019, doi: 10.31940/logic.v19i2.1418, 2019.

[9] D. Mishra, A. Vasal, and P. Tandon, "A Novel and Cost-Effective Approach to Public Vehicle Tracking System," International Journal of UbiComp (IJU), vol.3, no.1, pp. 33-44, 2012, doi:10.5121/iju.2012.3104.

[10] Ni San Hlaing, Ma Naing and San Naing, "GPS and GSM Based Vehicle Tracking System," International Journal of Trend in Scientific Research and Development, vol. 3, no. 4, pp. 271-275, 2019, doi: 10.31142/ijtsrd23718,2019.

[11] A. Barnagarwala and A. Buriwala, "Vehicle Tracking and Monitoring System using GPS and GSM/GPRS," in International Journal of Engineering Sciences \& Research Technology, vol. 6 pp. 17-21, 2017, doi: 10.5281 /zenodo. 1084326.

[12] A.S. Dinkar and S.A. Shaikh, "Design and Implementation of Vehicle Tracking System Using GPS," in Journal of Information Engineering and Applications, vol. 1, no.3, pp. 1-7, 2011. 
[13] B. Kodavati, V.K. Raju, S. Srinivasa Rao, A. V. Prabu, T. Appa Rao and Y.V. Narayana, "GSM and GPS Based Vehicle Location and Tracking System," in International Journal of Engineering Research and Applications (IJERA), vol 1, no. 3, pp. 616-625, 2020.

[14] O. Oheka and C. Tu, "Fast and Improved Real-Time Vehicle Anti-Tracking System," Applied Sciences.; vol. 10, no. 17, 5928, 2020, doi: 10.3390/app10175928.

[15] Jayati Routh, Arshiya das, Piyashi Kundu, Madhubarsha Thakur, "Automatic Vehicle Accident Detection and Messaging System Using GPS and GSM Module" in International Journal of Engineering Trends and Technology, vol. 67, no. 8, pp.69-72, 2019, doi: 10.14445/22315381/IJETT-V67I8P211.

[16] B. B. Lonkar and M. R. Sayankar, "Design and Implementation of Automatic Vehicle Tracker System for Accidental Emergency," ICCNS '16: Proceedings of the 6th International Conference on Communication and Network Security, November 2016, pp. 46-50, doi: 10.1145/3017971.3017988.

[17] V. Priyadarshni, P. G. Krishna and K. S. Ravi, "GPS and GSM Enabled Embedded Vehicle Speed Limiting Device," in Indian Journal of Science and Technology, vol. 9, 2016, doi: 10.17485/ijst/2016/v9i17/93045.

[18] S. Liawatimena and J. Linggarjati, "Vehicle Tracker with a GPS and Accelerometer Sensor System in Jakarta," in Internetworking Indonesia Journal, vol. 9, no.2, pp.9-15, 2017.

[19] M. Rathod, R. Gite, A. Pawar, S. Singh and P. Kelkar, "An air pollutant vehicle tracker system using gas sensor and GPS," 2017 International conference of Electronics, Communication and Aerospace Technology (ICECA) 2017, pp. 494-498, doi: 10.1109/ICECA.2017.8203734.

[20] B. Yang, M. Tang, S. Chen, G. Wang, Y. Tan and B. Li, "A vehicle tracking algorithm combining detector and tracker," in EURASIP Journal on Image and Video Processing, vol. 17, 2020, doi: 10.1186/s13640-020-00505-7.

[21] J. Jeong, H. Yoon and J. Park, "Reliable Road Scene Interpretation Based on ITOM with the Integrated Fusion of Vehicle and Lane Tracker in Dense Traffic Situation," in Sensors, no. 20, pp. 1-14, 2020, doi: 10.3390/s20092457.

[22] K. Verma, A. Kumar and D. Ghosh, "Robust Stabilised Visual Tracker for Vehicle Tracking," Defence Science Journal, vol. 68, pp. 307-315, 2018, doi: 10.14429/dsj.68.12209.

[23] M. Ershov, S. Smirnov, and V. Strotov, "Segmentation-based Vehicle Tracker for Real-Time Parameter Estimation on Smart Camera," 2020 9th Mediterranean Conference on Embedded Computing (MECO), 2020, pp. 1-4, doi: 10.1109/MECO49872.2020.9134363.

[24] W. Farag, "Real-time NMPC path tracker for autonomous vehicles," in Asian Journal of Control, pp.1-14, 2020, doi: 10.1002/asjc.2335.

[25] N. Ramli, M. Zabidi, A. Anuar and I. Musliman, "An open source LoRa based vehicle tracking system," Indonesian Journal of Electrical Engineering and Informatics (IJEEI), vol. 7, no. 2, pp. 221-228, doi: 10.11591/ijeei.v7i2.1174, 2019.

\section{BIOGRAPHY OF AUTHOR}

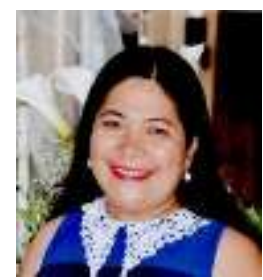

Dr. Narcisa T. Morallo was born on October 29, 1975. A Doctor of Philosophy in Technology Management from Cebu Technological University, Moalboal Campus. Currently assistant professor at Negros Oriental State University, Dumaguete City, Philippines. 